\title{
Memory for pictures and words as a function of level of processing: Depth or dual coding?
}

\author{
PAUL R. D'AGOSTINO \\ Gettysburg College, Gettysburg, Pennsylvania 17925 \\ and \\ BRIAN J. O'NEILL and ALLAN PAIVIO \\ University of Western Ontario, London, Ontario, Canada
}

\begin{abstract}
The experiment was designed to test differential predictions derived from dual-coding and depth-of-processing hypotheses. Subjects under incidental memory instructions free recalled a list of 36 test events, each presented twice. Within the list, an equal number of events were assigned to structural, phonemic, and semantic processing conditions. Separate groups of subjects were tested with a list of pictures, concrete words, or abstract words. Results indicated that retention of concrete words increased as a direct function of the processing-task variable (structural < phonemic < semantic). However, for both abstract words and pictures, phonemic and semantic processing produced equivalent memory performance. These data provided strong support for the dual-coding model.
\end{abstract}

Craik and his colleagues, in a series of recent papers, have described a depth-of-processing approach to memory (Craik \& Jacoby, 1975; Craik \& Lockhart, 1972; Craik \& Tulving, 1975; Lockhart, Craik, \& Jacoby, 1975). Within this framework, the memory trace is viewed as the product of the perceptual-encoding operations performed on the stimulus. Normally, encoding operations proceed in a relatively fixed sequence from a structural analysis to progressively more semantic analyses, with the number of encoding operations within each level or domain in part determined by the nature, predictability, and meaningfulness of the stimulus event (Craik \& Tulving, 1975; Lockhart, Craik, \& Jacoby, 1975). As encoding operations progress to deeper levels of analysis, trace elaboration increases, thereby increasing the accessibility of the memory trace at time of recall. Thus, trace elaboration and, hence, recall are critically determined by the qualitative nature of the encoding operations (Craik \& Tulving, 1975).

In a test of the depth hypothesis, Craik and Tulving (1975) required subjects to make judgments concerning the structural, phonemic, or semantic characteristics of concrete words exposed briefly on a tachistoscope. Under the structural-processing condition, subjects indicated whether a word was typed in capital letters;

This study was completed while the first author was on sabbatical leave at the University of Western Ontario. The research was supported by NSF Grant BMS75-04840 to Paul R. D'Agostino and by Grant A0087 from the National Research Council of Canada to Allan Paivio. We wish to thank Ruth Ramonas and Liz O'Neill for their assistance in data collection and analyses. Reprint requests should be sent to Paul $R$. D'Agostino, Department of Psychology, Gettysburg College, Gettysburg, Pennsylvania 17325. under the phonemic condition, subjects judged whether a word rhymed with another word; and, under the semantic-processing condition, subjects determined whether a word fit in a particular sentence frame. According to the depth position, structural, phonemic, and semantic decisions involve progressively deeper levels of encoding operations, and, therefore, it was predicted that subsequent retention would increase as a direct function of processing depth. As anticipated, semantic processing produced higher recall than did phonemic processing, which, in turn, exceeded structural processing. This result was obtained in both recognition and recall, under both incidental and intentional memory conditions.

While these data, as well as the results of several other studies (e.g., Craik, 1973; Hyde \& Jenkins, 1973; Schulman, 1971) are consistent with the depth position, they can also be interpreted within a dual-coding model of memory (Paivio, 1975). The dual-coding model assumes two independent but partially interconnected systems for encoding, storage, organization, and retrieval of stimulus information. The imagery system is specialized for processing nonverbal information stored in the form of images, that is, analogue representations of concrete things. The verbal system, on the other hand, is specialized for dealing with linguistic units. Independence of verbal and nonverbal codes implies that either code can be available and activated in varying degrees, depending on stimulus attributes and experimental task conditions. An important implication of this assumption is that the two codes can have additive effects on performance (Paivio, 1975). The assumption of interconnectedness implies that one code can activate the other, so that an image can be labeled and a word can evoke nonverbal images. 
Dual-coding theory also incorporates the idea of levels of information processing. These have been referred to as representational, referential, and associative levels, which refer to the degree of elaborative processing that is imposed on a stimulus event (Paivio, 1971, 1975). Processing to the representational level involves the activation of images by nonverbal stimuli and of verbal representations by linguistic events. Referential processing refers to the activation of one system by the other, such that a word may arouse an image or an image may activate a verbal code. Finally, associative processing refers to the activation of associations among representational units within each system, so that a verbal code can activate other verbal codes in an associative chain, and aroused images can activate other imaginal representations through interconnections within the imagery system.

Dual-coding theory can explain the depth-ofprocessing results in general, and the Craik and Tulving (1975) data in particular, in terms of the degree of representational, referential, and associative processing demanded by the particular orienting tasks used to define the depth manipulation. Orienting tasks that require only structural processing may not activate a representational response and, therefore, subsequent retention will be quite poor. Phonemic- and semanticorienting tasks insure the activation of a representational response and, therefore, recall will exceed that for the structural condition. Recall following a semanticorienting task should exceed recall following a phonemic task to the extent that the semantic task permits or encourages greater referential processing. This seems quite likely in the case of concrete words used by Craik and Tulving (1975). In the absence of referential processing, a semantic-orienting task might still produce higher levels of recall than would a nonsemantic task, if the two tasks produce differential amounts of associative processing. However, in the present context, it is assumed that the critical factor determining subsequent recall is the number of codes activated by the orienting task.

While the depth-of-processing and dual-coding positions are similar in some respects, they differ in terms of the critical factor responsible for memory performance. According to the depth hypothesis, retention is primarily determined by the final level, or depth, of the encoding operations performed on the stimulus, and, therefore, semantic processing should always produce higher levels of recall than does nonsemantic processing. According to the dual-coding hypothesis, retention is primarily determined by the number of codes and the type of code (verbal vs nonverbal) activated, rather than by the nature of the processing task per se. Thus, semantic processing which does not encourage dual coding or imagery need not produce higher levels of recall than does nonsemantic processing.
The present experiment was designed to test the dual-coding and depth hypotheses. The study was similar in design to those reported by Craik and Tulving (1975), in that subjects were required to make judgments concerning the structural, phonemic, and semantic characteristics of events briefly presented. However, in the present study, separate groups of subjects made these judgments on abstract words, concrete words, or pictures. According to the depth hypothesis, the level of encoding operations, as defined by the orienting tasks, should produce a comparable effect on recall for each type of material. That is, for each type of material, recall should increase as a direct function of the final level of processing induced by the orienting tasks. If, however, it is assumed that pictures are processed relatively directly to a deep semantic level, then this effect should hold for only abstract and concrete words. Dual coding, on the other hand, predicts that recall will increase as a direct function of the "depth" variable only under the concrete-word condition. Under the picture condition, dual coding should occur, with both the phonemic- and semantic-orienting tasks producing equivalent memory performance. Recall under both processing conditions should exceed the structural condition, in which only a single code should be activated. For abstract words, phonemic processing should produce higher recall than does structural processing, since only the rhyme judgment insures the activation of a representational response. However, since direct referential processing is not possible with abstract words, any difference between the phonemicand semantic-processing conditions should be minimal.

\section{METHOD}

\section{Design}

All subjects free recalled a list of 36 test events, each presented twice. Within the list, an equal number of events were assigned to the structural, phonemic, and semantic processing conditions. Under each processing condition, a correct response required a "yes" judgment for half of the events and a "no" judgment for the remaining items. Separate groups of subjects were assigned to the abstract-word, concrete-word, and picture conditions. Thus, type of material was manipulated as a between-subjects variable, while processing task and response judgment (yes-no) were manipulated within subjects.

\section{Materials and Lists}

A set of 36 abstract words was selected from the Paivio, Yuille, and Madigan (1968) norms. The mean imagery rating for this set of words was 3.59. A set of 36 black-and-white line drawings was selected from picture norms available at the University of Western Ontario. Thirty-two of the pictures had a labeling consistency index exceeding $93 \%$. The consistency index for the remaining four pictures ranged from $83 \%$ to $89 \%$. The pool of concrete words consisted of the names of these pictures. The mean imagery rating for the 20 concrete words for which normative data was available was 6.56 . The concrete and abstract words were carefully matched on the basis of rated familiarity and Thorndike-Lorge frequency.

For each of the abstract and concrete words, four sentence frames were constructed. For two of the sentence frames, 
insertion of the test event as subject or object produced a simple, meaningful, declarative sentence (e.g., "Uncontrolled power can be dangerous"; "The wheel rolled down the hill"). For the remaining two sentence frames, insertion of the test event produced a meaningless statement (e.g., "The residue stained the power"; "The wheel met a friend in the park"). In addition, for each abstract and concrete word, two words which rhymed with the test word and two words which did not were generated.

The test list consisted of 36 events, each presented twice at a constant lag of 11 items. In addition, three filler events were placed at the beginning of the list and three at the end of the list, in order to reduce primacy and recency effects. The test portion of the list was divided into three successive sections of 24 positions each. Within each list section, every within-subjects experimental condition ("yes" and "no" response judgments for structural, phonemic, and semantic tasks) was represented twice. Except for the restriction of a constant 11-item lag, assignment of the six experimental conditions to positions within each list section was random. Two such random orders (A and $B$ ) were devised.

The abstract and concrete words were each randomly divided into six groups of six words each. Picture groups conformed to the concrete-word groups. For each type of material, a 6 by 6 Latin square was used to assign the six groups of events to the six experimental conditions. For each type of material, four subjects were assigned to each row of the square, with two subjects receiving random Order $A$ and two receiving Order $B$. These procedures insured that, for each type of material, all events occurred equally of ten under all conditions, and that mean serial position was virtually constant for all experimental conditions.

\section{Procedure}

All subjects were tested under incidental memory conditions. For the abstract- and concrete-word conditions, the procedure was similar to that used by Craik and Tulving (1975). On each trial, the subject was asked a question about the next test word. Under the structural-processing condition, subjects were asked whether the next word was typed in uppercase letters; under the phonemic condition, subjects were asked whether the next word rhymed with a word read by the experimenter; and, under the semantic-processing condition, subjects were asked whether the next word made sense when inserted into the sentence frame read by the experimenter. When a test word was repeated, it occurred under the same experimental condition (e.g., sentenceyes) as on its first presentation, but, for the rhyme and sentence questions, an appropriate new word or sentence frame was used.

At the beginning of each trial, the subject sat looking in to the tachistoscope with a finger of the right hand resting on the "yes" response key and a finger of the left hand resting on the "no" response key. The experimenter gave a verbal ready signal, read the question, and, $2 \mathrm{sec}$ later, the test word was flashed for $500 \mathrm{msec}$. Subjects were instructed to be certain of their response before depressing the appropriate response key. Following each response, the experimenter recorded the reaction time, replaced the test card, and then gave the ready signal for the next trial. Approximately $15 \mathrm{sec}$ intervened between the subject's response and the next ready signal.

Under the picture condition, structural processing was induced by asking subjects whether the next picture was large. A small and large version of each picture was constructed such that the large version was twice the size of the small. The height or width of the small pictures ranged from 1.2 to $2.6 \mathrm{~cm}$. Prior to the presentation of the test list, subjects were given extensive size-discrimination training on a practice set of pictures. Under the phonemic-processing condition, subjects were asked whether the name of the next picture rhymed with a word read by the experimenter and, under the semantic-processing condition, they were asked whether the next picture made sense in a particular sentence frame.

Following the presentation of the list, subjects were allowed $5 \mathrm{~min}$ to free recall all test events. Under the picture condition, subjects were instructed to write down the names of the pictures. Following free recall, subjects under the picture condition were asked to label the 36 test pictures, and these labels were then used to score picture recall. Two subjects who reported anticipating the memory test were replaced.

\section{Subjects}

The subjects were 72 undergraduates at the University of Western Ontario. Subjects were randomly assigned to the abstract, concrete, and picture conditions and were tested individually.

\section{RESULTS}

The recall data were analyzed treating subjects and items as random factors and appropriate $\min \mathrm{F}^{\prime}$ values were computed. Only the results of the analysis by subjects are reported here, since, with the single exception noted below, the pattern of results was identical for each analysis.

The recall data are presented in Table 1 . Significant main effects were obtained for type of material $[\mathrm{F}(2,69)=29.88, \mathrm{p}<.001, \mathrm{MSe}=1.65]$, processing task $[\mathrm{F}(2,138)=79.72, \mathrm{p}<.001, \mathrm{MSe}=1.03]$, and response judgment (yes-no) $[\mathrm{F}(1,69)=33.98, \mathrm{p}<.001$, $\mathrm{MSe}=.81]$. However, the effect of the processing-task variable was dependent on the type of material presented $[\mathrm{F}(4,138)=3.88, \quad \mathrm{p}<.01, \quad \mathrm{MSe}=1.03$; $\left.\min F^{\prime}(4,329)=1.98, p<.10, \mathrm{MSe}=1.72\right]$. This interaction is summarized in Figure 1. Simple effects of processing task were significant for each type of material. A Tukey analysis indicated that, for both abstract words and pictures, phonemic and semantic

Table 1

Mean Proportion Correct Recall as a Function of Experimental Condition

\begin{tabular}{|c|c|c|c|c|}
\hline \multirow[b]{2}{*}{ Type of Material } & \multirow[b]{2}{*}{ Response Judgment } & \multicolumn{3}{|c|}{ Processing Task } \\
\hline & & Structural & Phonemic & Semantic \\
\hline Abstract Words & $\begin{array}{l}\text { Yes } \\
\text { No }\end{array}$ & $\begin{array}{l}.063 \\
.132\end{array}$ & $\begin{array}{l}.340 \\
.125\end{array}$ & $\begin{array}{l}.327 \\
.195\end{array}$ \\
\hline Concrete Words & $\begin{array}{l}\text { Yes } \\
\text { No }\end{array}$ & $\begin{array}{l}.132 \\
.153\end{array}$ & $\begin{array}{l}.431 \\
.202\end{array}$ & $\begin{array}{l}.514 \\
.410\end{array}$ \\
\hline Pictures & $\begin{array}{l}\text { Yes } \\
\text { No }\end{array}$ & $\begin{array}{l}.202 \\
.264\end{array}$ & $\begin{array}{l}.535 \\
.403\end{array}$ & $\begin{array}{l}.528 \\
.417\end{array}$ \\
\hline
\end{tabular}




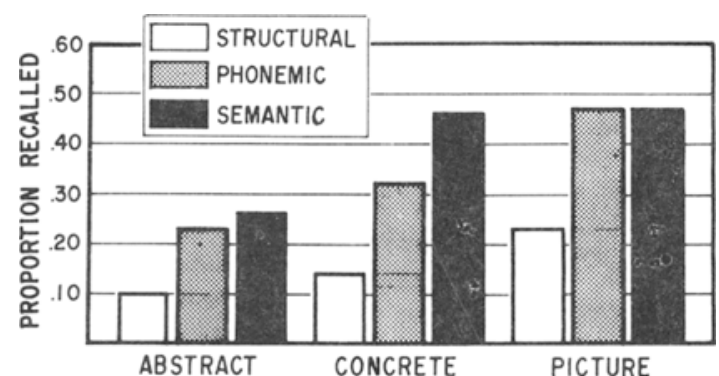

Figure 1. Mean proportion correct recall for abstract words, concrete words, and pictures as a function of processing task.

processing produced equivalent levels of recall which exceeded recall under the structural-processing condition $(\mathrm{p}<.01)$. For concrete words, semantic processing produced higher recall than did phonemic processing, which, in turn, was higher than structural processing $(p<.01)$. Simple effects of material were significant for each type of processing. A Tukey analysis indicated that, under both the structural- and phonemic-processing conditions, picture recall was superior to word recall $(\mathrm{p}<.05)$, but recall of concrete and abstract words did not significantly differ. With semantic processing, recall of concrete words and pictures did not differ, and recall for both types of material was superior to abstract-word recall $(\mathrm{p}<.01)$.

The Response Judgment (yes-no) by Processing Task interaction was also significant $[F(2,138)=20.81$, $\mathrm{p}<.001, \mathrm{MSe}=.93]$. It can be seen in Table 1 that this interaction resulted from the fact that "yes" judgments were remembered better than "no" judgments under the phonemic and semantic conditions, but not under the structural condition. No other interaction approached significance.

An analysis by subjects was performed on the mean median response latency for each experimental condition. Only correct judgments were included, and the significance level was set at $p<.01$. In general, response latencies for the second judgment were shorter than for the first judgment, "no" judgments took longer than "yes" judgments, latencies for abstract words were longer than for either concrete words or pictures, and reaction time increased across processing tasks. All the above main effects were qualified by one or more interactions. The decrease in reaction time from the first to the second presentation was more pronounced for "yes" judgments than for "no" judgments $[\mathrm{F}(1,69)=9.15, \mathrm{MSe}=7.43]$, and the decrease was less for structural processing than for phonemic or semantic processing $[\mathrm{F}(2,138)=7.43$, MSe $=8.65]$. The Processing Task by Type of Material by Response Judgment interaction was significant $[\mathrm{F}(4,138)=14.06, \mathrm{MSe}=14.27]$, and is summarized in Table 2. In the case of abstract words, the increase in reaction time across processing tasks was more pronounced for "no" than for "yes" judgments. For concrete words, the increase in reaction time across processing tasks was less affected by the responsejudgment variable. For pictures, reaction time for "yes" judgments increased with processing task, but for "no" judgments, the longest response latency occurred with phonemic processing. This probably resulted from the need to examine possible alternative labels for a picture before making a "no" decision. It is of interest to note that semantic decisions were slowest for abstract words and most rapid for pictures. With exception of long latencies for abstract words under the semantic-no condition and for pictures under the phonemic-no condition, the pattern of response latencies is similar to those reported by Craik and Tulving (1975). The present data add little new information and, therefore, will not be discussed further.

\section{DISCUSSION}

The results indicate that memory performance increased as a direct function of the processing-task variable only under the concrete-word condition. For both pictures and abstract words, memory performance was poorest following structural processing, but there was little or no difference between the phonemic- and semantic-processing conditions. The data provide complete confirmation of the predictions generated from the dual-coding model.

As noted earlier, the depth hypothesis assumes that

Table 2

Mean Median Response Latency in Milliseconds as a Function of Type of Material, Processing Task, and Response Judgment

\begin{tabular}{|c|c|c|c|c|}
\hline \multirow[b]{2}{*}{ Type of Material } & \multirow[b]{2}{*}{ Response Judgment } & \multicolumn{3}{|c|}{ Processing Task } \\
\hline & & Structural & Phonemic & Semantic \\
\hline Abstract Words & $\begin{array}{l}\text { Yes } \\
\text { No }\end{array}$ & $\begin{array}{l}659(.03) \\
705(.01)\end{array}$ & $\begin{array}{l}802(.05) \\
818(.01)\end{array}$ & $\begin{array}{l}1,010(.08) \\
1,202(.16)\end{array}$ \\
\hline Concrete Words & $\begin{array}{l}\text { Yes } \\
\text { No }\end{array}$ & $\begin{array}{l}651(.03) \\
639(.03)\end{array}$ & $\begin{array}{l}724(.05) \\
760(.04)\end{array}$ & $\begin{array}{l}875(.13) \\
866(.03)\end{array}$ \\
\hline Pictures & $\begin{array}{l}\text { Yes } \\
\text { No }\end{array}$ & $\begin{array}{l}650(.03) \\
726(.12)\end{array}$ & $\begin{array}{l}742(.06) \\
926(.06)\end{array}$ & $\begin{array}{l}788(.09) \\
794(.03)\end{array}$ \\
\hline
\end{tabular}

Note-Numbers in parentheses indicate mean proportions of errors. 
retention is primarily determined by the final level of encoding operations performed on the stimulus and, therefore; it predicts that semantic processing should produce higher recall than either structural or phonemic processing. In the present study, the predicted pattern of recall was obtained only for concrete words. It is possible for the depth hypothesis to account for picture recall, if it is assumed that pictures are processed to a deep semantic level when they are named, but not when attention to a physical characteristic such as size is required. However, it is not clear how a depth approach would explain the pattern of recall for abstract words.

The dual-coding model also provides an explanation for the difference in recall of pictures, abstract words, and concrete words, under the various processing-task conditions. The fact that picture recall was superior to word recall following structural processing is interpreted to mean that a size judgment for pictures was more likely to activate a representational response than a case judgment for words. With phonemic processing, the difference in the recall of concrete and abstract words (8\%) was not reliable, and picture recall was again superior to word recall. The data are consistent with dual coding, if it is assumed that the rhyme judgment required that pictures be named and, therefore, dual coding was more likely with pictures than with words. Under the semantic-processing condition, recall for concrete words and pictures was virtually identical, and superior to recall of abstract words. In this case, it is argued that the sentence-judgment task encouraged referential processing and, hence, dual coding for both pictures and concrete words.

One aspect of the present data cannot be explained in terms of the number of available memory codes. Under the phonemic and semantic conditions, "yes" judgments for both pictures and words produced higher recall than did "no" judgments. Schulman (1974), as well as Craik and Tulving (1975) have previously reported the same finding with verbal material. Craik and Tulving suggest that the higher retention of positive decisions may be related to both trace elaboration and compatibility of the memory code with existing structures in semantic memory. The present data are consistent with this interpretation, if it is assumed that trace elaboration or associative processing, as well as degree of correspondence with existing memory structures, are important determinants of retrieval from both the verbal and nonverbal systems.

The primary data of the present experiment provide strong support for dual-coding theory. A depth hypothesis apparently cannot fully explain these data without the addition of assumptions which would render it functionally equivalent to a dual-coding model.

\section{REFERENCES}

Craik, F. I. M. A "Levels of Analysis" view of memory. In P. Pliner, L. Kramer, \& T. M. Alloway (Eds.), Communication and affect: Language and thought. New York: Academic Press, 1973.

CRaIK, F. I. M., \& JACOBY, L. L. A process view of short-term retention. In F. Restle (Ed.), Cognitive theory: (Vol. I). Potomac, Md: Erlbaum, 1975.

Craik, F. I. M., \& Lockhart, R. S. Levels of processing: A framework for memory research. Journal of Verbal Learning and Verbal Behavior, 1972, 11, 671-684.

Craik, F. I. M., \& Tulving, E. Depth of processing and the retention of words in episodic memory. Journal of Experimental Psychology: General, 1975, 104. 268-294.

Hyde, T. S., \& Jenkins, J. J. Recall for words as a function of semantic, graphic, and syntactic orienting tasks. Journal of Verbal Learning and Verbal Behavior, 1973, 12, 471-480.

Lockhart, R. S., Craik, F. I. M., \& Jacoby, L. L. Depth of processing in recognition and recall: Some aspects of a general memory system. In J. Brown (Ed.), Recognition and recall. London: Wiley, 1975.

Paivio, A. Imagery and verbal processes. New York: Holt, Rinehart, \& Winston, 1971(Chapter 3).

PaIvio, A. Coding distinctions and repetition effects in memory. In G. H. Bower (Ed.), The psychology of learning and motivation (Vol. 9). New York: Academic Press, 1975.

Paivio, A., Yuille, J. C., \& Madigan, S. Concreteness, imagery, and meaningfulness values for 925 nouns. Journal of Experimental Psychology, Monograph Supplement, 1968, 76(1, Part 2).

Schulman, A. 1. Recognition memory for targets from a scanned word list. British Journal of Psychology, 1971, 62, 335-346.

Schulman, A. I. Memory for words recently classified. Memory \& Cognition, 1974, 2, 47-52.

(Received for publication August 9, 1976; revision roceived November 23,1976 .) 